\title{
Proactivity as a Factor of Satisfaction with Distance Learning during Lockdown from the Perspective of Students' Perception and Preferences
}

\author{
Nadezhda Sivrikova ${ }^{1, *}$, Tatyana Ptashko ${ }^{1}$, Elena Chernikova $^{1}$, Artem Perebeynos ${ }^{1}$, Elena Kharlanova $^{1}$ and Fedor \\ Ivanov $^{1}$ \\ ${ }^{1}$ South Ural State Humanitarian Pedagogical University, Department of Social Work, Pedagogy and Psychology, Chelyabinsk, \\ Russian Federation, Lenin prospect 69, Russia
}

\begin{abstract}
During the first wave of COVID-19, universities in many states switched to distance learning. Students faced the challenge of moving quickly from face-to-face to distance learning. This created the prerequisites for analysing this new experience for Russian universities. There are many studies analysing satisfaction with online learning. Nevertheless, they were conducted in the period of voluntary transition to this form of learning and outside the context of proactivity. This paper attempts to address this kind of research gap and answer the question of the correlation between satisfaction with distance learning during the lockdown and students' attitudes towards proactivity. After switching to distance learning in the spring of 2020, students answered questions in an online questionnaire. 386 people (212 women and 174 men) took part in the survey. The age of participants was 17-21 years. The results of the study showed that 1) students do not have negative feelings about distance learning; 2) students still prefer face-to-face learning, and distance (online) learning is perceived as additional or temporary measure; 3 ) during the lockdown, students showed a mild tendency to react reactively to the situation; 4) proactive attitudes of students affect the degree of their satisfaction with distance learning.
\end{abstract}

Keywords: learning satisfaction; proactive behaviour; reactive behaviour; distance learning; pandemic; proactive attitude; coronavirus

\section{Introduction}

The experience with the COVID-19 pandemic has accelerated the digital transformation of education. In many states, lockdown was introduced in connection with the outbreak of the disease, and educational institutions switched to distance learning. This led to the fact that at the initial stage of the fight against the spread of the virus, educational institutions faced many difficulties - from "falling" due to server overloads to "falling" due to teacher fatigue [1]. From the point of view of the administration, the teachers' work schedule should have become less demanding; however, in practice, universities faced the opposite situation. Students also faced many difficulties. This led to anxiety among parents who were afraid that children would not be able to master the educational program on their own independently. As a result, teachers "bombarded" with the students'work, papers, and homework of students, which had to be quickly checked and commented on in detail, providing feedback to the students.

Currently, the benefits of information and communication technologies in learning are not disputed, unlike distance learning [2]. The obvious advantages of this form of learning include flexible schedule, relatively low costs, the acquisition of additional competencies in the use of information and communication technologies. Typical barriers to the introduction of distance learning are e.g. bias, negative experience, technical illiteracy and insufficient technical equipment, gender specifics of Internet use, the gap between the theory and practice of e-learning [3]. Researchers believe that many educational institutions, especially in third world countries, are not prepared to solve problems related to the supply of high-quality distance courses [4]. However, preliminary studies in developing countries have shown that distance learning can meet the needs of students, including in educational institutions where this technology was not previously used [5].

During the COVID-19 outbreak, distance learning was seen as the best option for ensuring the safety of students and their environment [6]. In Russia, the coronavirus pandemic has led to the mobilization of existing Internet technologies in education: communication infrastructure, digital learning resources, convenient teaching tools, effective teaching methods, educational organizations, support services for teachers, parents and students, and a system of interaction between the government and schools. All schools and institutions of higher education were pushed online. Life itself

\footnotetext{
* Corresponding author: bobnv79@mail.ru
} 
started a large-scale experiment, the short and long-term consequences of which have yet to be evaluated by scientists. However, the undeniable consequence of the experience gained was the readiness and easy switching of universities to distance learning during the second and third wave of COVID-19. Subsequently, quarantine measures were not as large as in 2020. They were applied locally in individual educational institutions or for individual educational groups.

As a result, distance learning has now become a familiar tool to prevent pandemic situations without suspending the educational process. But only few studies are devoted to assessing the effectiveness of this form of education in a situation where the transition to it is not voluntary for students. The forced nature of the transition to distance learning can have a significant impact on their attitude towards this form of education, causing protest among students and their parents.

\section{Literary research}

Satisfaction with distance learning is defined as the student acceptance of this format and the level of comfort associated with its use [7]. Researchers consider global satisfaction (general attitude to distance learning) and differentiated satisfaction (i.e., satisfaction with the sides of individual actors in distance learning). An example of the latter is the blended e-learning satisfaction (BELS) model. This model includes the following factors: self-effectiveness, performance productivity, system functionality, content features, interaction, and psychological climate [8].

Satisfaction with the educational process consists of three components: cognitive, emotional, and behavioural. The cognitive component consists in assessing the positive and negative aspects of distance learning. The emotional component is a positive or negative attitude towards the experience of distance learning and its individual elements. The behavioural component is expressed by the readiness to continue distance learning or to recommend similar training to other people.

Researchers from different countries have repeatedly studied the degree of student satisfaction with distance learning. Until recently, however, these studies have been conducted predominantly in mixed education [2,9,10] or continuing education in the workplace [11-13]. A large number of studies deal with the analysis of the effectiveness of individual elearning tools [3,14-16]. Previous studies show that students have a positive attitude towards e-learning. For example, the study by R. R. Codilan indicates that students appreciate the availability of e-learning [15]. According to another study, university students in Malaysia have a positive attitude towards e-learning and intend to practice it for educational purposes. [17] The experience of introducing distance learning elements at the Siberian Federal University shows that $15 \%$ of its students and $11 \%$ of its teachers are satisfied with its academic effectiveness [17]. Most previous studies were conducted in the context of voluntary consent to e-learning. Only recently, studies appeared that analyse the level of satisfaction with distance learning during lockdown. Their results are contradictory. For example, the results of studies show that distance learning of physiotherapy aroused negative feelings among students in Australia [19], while in Italy, students were as satisfied with distance learning of physiotherapy as in the case of face-to-face learning [20].

According to research in Russia, the negative attitude towards distance learning during the lockdown is due to the lack of students' self-organization skills, the inability to take responsibility for their education [1]. This suggests that the level of student activity is an important internal factor of satisfaction with distance learning during the lockdown period. This term describes the ability of a person to distinguish himself/herself from other human beings. It consists of the ability to take the initiative to set and achieve their own goals in a difficult situation, even if nothing in the inner circle provokes them to do so [21].

Proactiveness correlates with motivation and positive results of the activity. For example, the level of proactivity in everyday life is associated with the satisfaction with activities [21]. This suggests that the level of student proactivity is related to the level of satisfaction with distance learning.

Thus, distance learning seems to be a feasible option to face the COVID-19 pandemic. But this requires a positive attitude of students. Therefore, proactivity can be a resource that contributes to the success of adapting to distance learning. The aim of this study is to examine the correlation between the level of proactivity and satisfaction with distance learning during the lockdown and to empirically demonstrate this fact.

\section{Methodology}

\subsection{Study design}

The research question is whether proactivity has an impact on the satisfaction with distance learning during lockdown. The questionnaire survey was conducted using the online resource Google Forms after the first lockdown in Russia in June 2020. Calls for student involvement in the study were made through joint student council groups. Participation in the survey was voluntary.

The participants were students (aged 17 to 21 years) from state universities of Russia. A total of 386 students participated in the survey. The research sample consisted of 174 male students (45\%) and 212 female students (55\%). 
To answer the research question, the following hypothesis was formulated: There is a statistical correlation between proactivity and satisfaction with distance learning during the lockdown. The hypothesis is based on proactivity as a prerequisite for self-determination in an unfamiliar situation. Based on this, students who set educational goals are expected to be more satisfied with distance learning during the lockdown.

\subsection{Instruments}

The questionnaire consists of 4 sets of questions. The first set of questions is aimed at identifying satisfaction with distance learning. The set consists of 5 items measurable on 5-point Likert scale. The second set of questions is aimed at determining the cognitive component of satisfaction with distance learning. It contained 8 items where students were asked to choose one or more of the proposed options. Students can give their own answer too. The third set includes questions aimed at assessing the behavioural component of satisfaction with distance learning. The set consists of 2 items measurable on 5-point Likert scale. The fourth set of the questionnaire contains 2 questions describing the level of student proactivity in learning. The first question concerns the changes in student activity during the lockdown. The second issue concerned is the level of achievement of learning goals during the lockdown.

In order to verify the reliability of the questionnaire, we calculated Cronbach's alpha. The result obtained confirms the adequate internal consistency of the tool for this study (Table 1).

Table 1. Reliability indicators of scales satisfaction with distance learning

\begin{tabular}{|l|c|c|}
\hline \multicolumn{1}{|c|}{ Scale } & Cronbach's Alpha & Number of items \\
\hline The emotional component of satisfaction with distance learning & 0.744 & 5 \\
\hline The cognitive component of satisfaction with distance learning & 0.68 & 8 \\
\hline The behavioural component of satisfaction with distance learning & 0.94 & 2 \\
\hline
\end{tabular}

Source: Authors' calculation-SPSS.

In order to achieve the objectives of the study, correlation analyses were performed using the statistical software SPSS v.23.

\section{Results and Discussion}

The results of the study show that the activity of students during the period of forced isolation did not change $(X=2.87) .9 .6 \%$ of respondents noted that their activity increased during the pandemic. The number of students who noted a decrease in their activity was $15.5 \%$ (Table 2).

In general, students believe that distance learning did not affect the level of achievement of their educational goals $(X=3.01)$. Some participants $(10.4 \%)$ noted that distance learning had a positive effect on this (Table 2).

Distance learning created obstacles in achieving educational goals for $11.7 \%$ of the respondents. Educational activity "decreased" in the case of $15.5 \%$ of the respondents, "rather decreased" for $20.7 \%$ of the respondents, "did not change" for $34.2 \%$ of the respondents, "rather increased" in $19.9 \%$ of the respondents, and "definitely increased" in $9.6 \%$ of cases. Distance learning "has clearly contributed" to the achievement of their educational goals in 10.4\% of the cases, "rather contributed" to their achievement for $23.6 \%$ of the respondents, "did not affect the achievement of the goals" for $32.6 \%$ of the respondents, "rather created an obstacle to their achievement" for $21.8 \%$ of the respondents, "thwarted their achievement" for $11.7 \%$ of the respondents.

Table 2. Level of student proactivity during lockdown

\begin{tabular}{|c|c|c|}
\hline Likert scale & Activity change & Achieving the Goal \\
\hline 1 & $15.5 \%$ & $10.4 \%$ \\
\hline 2 & $20.7 \%$ & $23.6 \%$ \\
\hline 3 & $34.2 \%$ & $32.6 \%$ \\
\hline 4 & $19.9 \%$ & $21.8 \%$ \\
\hline 5 & $9.6 \%$ & $11.7 \%$ \\
\hline Number of respondents & 386 & 386 \\
\hline
\end{tabular}




\begin{tabular}{|c|c|c|}
\hline Mean & 2.87 & 3.01 \\
\hline Minimum & 1 & 1 \\
\hline Maximum & 5 & 5 \\
\hline
\end{tabular}

Source: Authors' calculation - SPSS.

It can be concluded that during the lockdown, students showed proactive behaviour to varying degrees. In the research sample, about $30 \%$ of the students showed a proactive attitude in the process of distance learning, and the same number showed a tendency to reactive behaviour. The remaining $30 \%$ did not notice any changes in their own activity during the pandemic. A similar situation was in assessing the achievement of educational goals.

Students' satisfaction with distance learning during the lockdown period is shown in Table 3.

Table 3. Level of satisfaction with distance learning during lockdown

\begin{tabular}{|c|r|r|c|}
\hline \multirow{2}{*}{ Likert scale } & \multicolumn{3}{|c|}{$\begin{array}{c}\text { Distance Learning Satisfaction } \\
\text { Components }\end{array}$} \\
\cline { 2 - 4 } & emotional & \multicolumn{1}{c|}{ cognitive } & behavioural \\
\hline 1 & $13.0 \%$ & $9.6 \%$ & $16.3 \%$ \\
\hline 2 & $31.6 \%$ & $24.9 \%$ & $18.1 \%$ \\
\hline 3 & $35.0 \%$ & $28.0 \%$ & $20.2 \%$ \\
\hline 4 & $20.5 \%$ & $30.1 \%$ & $19.9 \%$ \\
\hline $\begin{array}{c}\text { Number of } \\
\text { respondents }\end{array}$ & $38 \%$ & $7.5 \%$ & $25.4 \%$ \\
\hline Mean & 2.99 & 3.24 & 386 \\
\hline Std. deviation & 0.91 & 1.11 & 1.39 \\
\hline Minimum & 1.0 & 1.00 & 1.0 \\
\hline Maximum & 4.8 & 5.0 & 5.0 \\
\hline
\end{tabular}

Source: Authors' calculation-SPSS

At the same time, the emotional component of the analysed phenomenon was rated the lowest.

About $30 \%$ of the respondents tend to have rather a positive attitude towards distance learning, but the same percentage tend to have rather a negative attitude (see Table 3). About $37.6 \%$ of the respondents believe that distance learning was organized at a sufficient level. However, $28 \%$ of the respondents found it difficult to say how well distance learning was organized during the pandemic. $34.5 \%$ of the respondents participating in the study believe that the organization of distance learning was unsatisfactory. About $45 \%$ of the respondents demonstrated a negative behavioural attitude towards distance learning.

The results of the study show that the students who took part in the research found the idea of switching to distance learning during the pandemic positive $(40 \%)$ or rather positive $(26.5 \%)$. This idea was perceived negatively by $10 \%$ of the students, and rather negatively by other $12.7 \%$ of the students. However, $60.6 \%$ of the respondents consider distance learning a forced measure caused by the need to prevent the spread of the pandemic. $37.7 \%$ believe that they have fully mastered and can continue their studies in the form of distance learning. At the same time, the idea of combining distance and classical forms of education was divided: $25.4 \%$ of the respondents perceive this idea positively, $20.9 \%$ rather positively, $13 \%$ negatively and $20.9 \%$ rather negatively.

It can be concluded that the students show a neutral attitude towards distance learning. The forced transition to online learning during the pandemic did not arouse positive emotions in them. They were able to adapt and are ready to switch again to distance learning if necessary. According to the students, distance learning represents a complement or an additional element to the traditional form of study. Students do not see distance learning as an equivalent alternative to traditional forms of learning. The experience the students gained during the pandemic did not arouse their interest in distance learning, because it was associated with many problems and difficulties. 
The Spearman correlation coefficient was used to determine the relationship between the variables under review. Table 4 presents a matrix of correlations between the parameters of satisfaction with distance learning and student activity during the pandemic.

Correlations exist between proactivity and satisfaction elements of distance learning during the lockdown. According to the data obtained, the level of activity and achievement of the goal correlates with three components of satisfaction with distance learning (emotional, cognitive, and behavioural). In this case, correlation coefficients are higher in the case of the relationship between the degree of achievement of educational goals and satisfaction than between the degree of activity and satisfaction.

In fact, students who noted an increase in their level of activity during the pandemic were more satisfied with distance learning than students who noted a decrease in their level of activity. And students who claimed that distance learning contributed to achieving their educational goals were more satisfied with distance learning during the pandemic than students for whom distance learning represented an obstacle to achieving educational goals.

Thus, the study confirms the existence of a direct relationship between the level of proactivity and satisfaction with distance learning during the pandemic.

Table 4. Correlations between proactivity scores and life satisfaction components

\begin{tabular}{|c|c|c|c|c|}
\hline \multicolumn{2}{|c|}{ Test parameters } & \multicolumn{3}{c|}{ Distance Learning Satisfaction Components } \\
\cline { 2 - 5 } & & emotional & cognitive & behavioral \\
\hline \multirow{3}{*}{$\begin{array}{c}\text { Activity } \\
\text { change }\end{array}$} & $\mathrm{r}_{\mathrm{s}}$ & 0.41 & 0.37 & -0.36 \\
\cline { 2 - 5 } & $\mathrm{p}$ & 0.0001 & 0.0001 & 0.0001 \\
\cline { 2 - 5 } & $\mathrm{n}$ & 386 & 386 & 386 \\
\hline \multirow{3}{*}{$\begin{array}{c}\text { Achieving } \\
\text { the Goal }\end{array}$} & $\mathrm{r}$ & 0.69 & 0.58 & -0.68 \\
\cline { 2 - 5 } & $\mathrm{p}$ & 0.0001 & 0.0001 & 0.0001 \\
\cline { 2 - 5 } & $\mathrm{n}$ & 386 & 386 & 386 \\
\hline
\end{tabular}

Source: Authors' calculation - SPSS.

The study enabled the identification of the students' attitude towards distance learning in the case of lockdown. During the pandemic, satisfaction with distance learning was moderate rather than high. Students consider this to be a forced temporary measure. They prefer the traditional (face-to-face) form of learning. A similar pattern can be seen in Italy [20] and Australia [19].

There are data that indicate a more negative attitude of students. In Ukraine, the level of satisfaction with the content of the course, its form, and teaching methods within distance learning is significantly lower than those shown in this study $(1 \%-7 \%)[3]$.

Such discrepancies in data can be explained by several reasons: differences in the organization of distance learning, the level of readiness of students and teachers to switch to distance learning format, the possibility of choice. In the universities participating in this study, the transition to distance learning was rapid and forced. Not all teachers and students were ready for this form of interaction. Teachers created e-learning materials under pressure of time. At the same time, new distance learning technologies (for example, Zoom conferences) were being developed. As a result, more than $50 \%$ of the students faced technical problems, and about $30 \%$ of the students $(48.8 \%$ of them in their last year of study) complained about insufficient computer literacy of teachers. About $20 \%$ of the students mentioned their own computer illiteracy. The generation gap concerning the use of technology by digital natives (students) and digital immigrants (teachers) may have affected this case [22]. This has affected the learning process and results. Reading literature replaced lectures; seminars were replaced by individual work and performance of practical tasks. This form of distance learning corresponded rather to self-study and caused resistance from the side of students. However, a positive fact is that more than half of the respondents saw their laziness as an obstacle they had to fight with. This obstacle is a major problem in the organization of self-study. The lack of technical opportunities for distance learning was perceived negatively by $22 \%$ of the students.

The experience of the general forced immediate transition to distance learning shows that at this stage universities were able to ensure maximum security for students by switching to distance learning. However, the quality of such education was at a satisfactory level only and did not meet the optimistic forecasts made earlier. This is partly due to the internal attitude of students.

The study shows the reactive position of most students in the situation of forced transition to distance learning. This is evidenced by the fact that only $16.8 \%$ of the students see this experience as a new opportunity, $12.3 \%$ strive to achieve their educational goals, and $7.1 \%$ of the students noticed their increased activity. This corresponds to the data on the prevalence of proactive attitudes among students, specifically $8 \%$ of young people aged $17-24$ years, more often expressed by men (10\%) than by women (8\%) [23]. 
On the other hand, according to the results of the study, the level of proactivity is associated with the level of satisfaction with distance learning. This confirms the hypothesis that the ability to work independently, the ability to set their own educational goals contribute to a more positive perception of the forced transition to another form of learning. This is reflected in the fact that proactive students more often show a positive attitude towards e-learning, are able to highlight the constructive aspects of distance learning, and are ready to study from home.

\section{Conclusion}

The Covid-19 pandemic showed that the transition of education to distance learning during the lockdown is a reality of Russian higher education. This situation indicates the need to find conditions and resources to make the transition to distance learning as comfortable and effective as possible. Indirect data from previous studies indicate that satisfaction with distance learning depends on student proactivity. This paper focused on confirming this assumption through an analysis of students' subjective perceptions and preferences. In this context, we tried to answer the question of whether there is a correlation between proactive attitude and the level of satisfaction with distance learning during the lockdown. The results showed that the change in activity level and the presence of own educational goals during the lockdown correlates with the level of satisfaction with distance learning. This is true for all three components of satisfaction: emotional, cognitive, and behavioural.

In the future, we plan to study the impact of proactivity on satisfaction with distance learning in a situation of voluntary choice. It is important to study the impact of experience on this process too. The transition to distance learning was carried out during other waves of Covid-19 too. Therefore, the perceived satisfaction might change.

\section{References}

1. M. A. Lukashenko. Self-management skills as a basis for the effectiveness of e-learning. Psychology. 30, 61-70 (2021)

2. T. C. Herrador-Alcaide, M. Hernández-Solís, R. Sanguino Galván. Feelings of satisfaction in mature students of financial accounting in a virtual learning environment: an experience of measurement in higher education. International Journal of Educational Technology in Higher Education, 16(20) (2019)

3. S. Dovbenko, R. G. Naida, V. M. Beschastnyy, H. V. Bezverkhnia, V. V. Tsybulska. Problem of Resistance to the Introduction of Distance Learning Models of Training in the Vocational Training of Educators. International Journal of Learning, Teacher, Educational Research. 19, 1-12 (2020)

4. H. Abuhassna, M. A. Z. M. Zakaria, N. Yahya, A. B. M. Kosnin, W. M. Al-Rahmi. Examining students's satisfaction and learning autonomy through web-based courses. International Journal Advanced Trends in Computer Science and Engineering. 9, 356-70 (2020)

5. D. Sulisworo, D. A. Kusumaningtyas, T. Handayani, E. Nursulistiyo. The learning design and student's response to physics online learning in rural school of Indonesia. International Journal of Innovative Technology and Exploring Engineering. 9, 4999-5006 (2019)

6. G. Basilaia, M. Dgebuadze, M. Kantaria, G. Chokhonelidze. Replacing the Classic Learning Form at Universities as an Immediate Response to the COVID-19 Virus Infection in Georgia. International Journal of Research Applied Science \& Engineering Technology. 8, 101-8 (2020)

7. R. Rachmawati, E. Octavia, S. Dewi Herawati, O. Sinaga. Culture, Environment and E-learning as Factor in Student Performance (Case Studies in Management Accounting Study Programs). Universal Journal of Educational Research. 7, 72-8 (2019)

8. J. H. Wu, R. D. Tennyson, T. L. Hsia. A study of student satisfaction in a blended e-learning system environment. Computers \& Education. 55, 155-64 (2010)

9. L. Zhou, S. Wu, M. Zhou, F. Li. 'School's Out, But Class' On', The Largest Online Education in the World Today: Taking China's Practical Exploration During The COVID-19 Epidemic Prevention and Control As an Example. SSRN. 4, 501-19 (2020)

10. A. Al-Awamleh. Students' satisfaction with blended learning programmes in the Faculty of Physical Education. Science of Education Today. 9, 37-47 (2019)

11. J. Rodríguez-Santero, J. J. Torres-Gordillo, J. Gil-Flores. Confirmatory Factor Analysis of a Questionnaire for Evaluating Online Training in the Workplace. Sustainability. 12, 4629 (2020)

12. M. H. Song, T. I. Han. A study on the learning satisfaction and work utilization of the teacher safety e-learning. International Journal of Information and Education Technology. 9, 909-17 (2019) 
13. Gopinathan, S. Praveen Kumar, Pothumani. Customer satisfaction in career enhancement with the usage of ELearning software. International Journal of Recent Technology and Engineering (IJRTE). 8, 466-8 (2019)

14. C. L. Bian, D. L. Wang, S. Y. Liu, W. G. Lu, J. Y. Dong. Adaptive learning path recommendation based on graph theory and an improved immune algorithm. Koreanstudies Information Service System. 13, 2277-98 (2019)

15. R. R. Codilan. Efficiency and Acceptability of a Customized e-learning Platform in a Philippine State University and College. Indian Journal of Computer Science Engineering. 10, 83-8 (2019)

16. D. Padmo, L. Sri Ardiasih. The utilization of mobile devices for improving access to online learning for distance education's students. Turkish Online Journal of Distance Education. 20, 147-61 (2019)

17. M. M. Alamri, V. M. Al-Rahmi, N. Yahaya, A. M. Al-Rahmi, H. Abualrejal, A. M. Zeki, Q. Al-Maatouk. Towards adaptive e-learning among university students: By applying technology acceptance model (TAM). International Journal of Engineering Advanced Technology. 8, 270-6 (2019)

18. O. Smolyaninova, E. Bezyzvestnykh. Implementing Teachers' Training Technologies at a Federal University: Eportfolio, Digital Laboratory, PROLog Module System. International Journal of Online and Biomedical Engineering (iJOE). 15(4), 69 (2019)

19. L. Ng, K. C. Seow, L. MacDonald, C. Correia, A. Reubenson, P. Gardner, A. L. Spence, S. Bunzli, B. I. R. De Oliveira. eLearning in Physical Therapy: Lessons Learned From Transitioning a Professional Education Program to Full eLearning During the COVID-19 Pandemic. Physical Therapy. 101, 1-9 (2021)

20. G. Rossettini, T. Geri, A. Turolla, A. Viceconti, C. Scumà, M. Mirandola, A. Dell'Isola, S. Gianola, F. Maselli, A. Palese. Online teaching in physiotherapy education during COVID-19 pandemic in Italy: a retrospective casecontrol study on students' satisfaction and performance. BMC Medical Educaction. 21, 1-7 (2021)

21. F. Lieder, G. Iwama. Toward a formal theory of proactivity. Cognitive, Affective, \& Behaviroal Neuroscience. 21, 490-508 (2021)

22. S. Dickinson. Post-traumatic growth in the twenty-first century: how current trends may threaten our ability to grow after trauma. The Journal of Positive Psychology, 16(4), 1-9 (2020) 